Hubel, Brian A.; Goodhue, Mark; Lee, Landris T. Erosion

Verfügbar unter / Available at:

https://hdl.handle.net/20.500.11970/100302

Vorgeschlagene Zitierweise / Suggested citation:

Hubel, Brian A.; Goodhue, Mark; Lee, Landris T. (2010): A Life Cycle Approach to Probabilistic Assessment of Levee Erosion. In: Burns, Susan E.; Bhatia, Shobha K.; Avila, Catherine M. C.; Hunt, Beatrice E. (Hg.): Proceedings 5th International Conference on Scour and Erosion (ICSE-5), November 7-10, 2010, San Francisco, USA. Reston, Va.: American Society of Civil Engineers. S. 263-272. 


\title{
A Life Cycle Approach to Probabilistic Assessment of Levee Erosion
}

\author{
Landris T. Lee ${ }^{1}$, P.E., Brian A. Hubel ${ }^{2}$, P.E., G.E., and Marc J. Goodhue ${ }^{3}$, P.E.
}

${ }^{1}$ Research Civil Engineer, U.S. Army Engineer Research and Development Center, 3909 Halls Ferry Rd., Vicksburg, MS 39180

${ }^{2}$ Senior Civil Engineer, U.S. Army Corps of Engineer San Francisco District GeoSciences Section, 1455 Market Street, San Francisco, CA 94103

${ }^{3}$ Geo-Sciences Section Chief, U.S. Army Corps of Engineer San Francisco District Geo-Sciences Section, 1455 Market Street, San Francisco, CA 94103

\begin{abstract}
A methodology to assess the erosion-induced breaching probability (i.e. probability of unsatisfactory performance) of clay levees exposed to coastal and riverine hydrodynamic loading was developed for selected levee reaches, and has application to levee life-cycle maintenance planning. The methodology applies probabilistic erosion relationships including water-side storm surge and wave runup with or without concurrent land-side overtopping. The method provides a means to forecast levee maintenance and flood risk reduction costs by estimating future erosion damage from episodic or cumulative storm events.
\end{abstract}

\section{INTRODUCTION}

The successful long-term performance of an earthen levee structure exposed to flooding, storm surge, river currents, or coastal wave action depends upon its structural resilience to the external hydrodynamic loads (illustrated in Figure 1). Erosion of the outer slope (water-side), crest, or inner slope (land-side) requires an initiating external force (energy, pressure, or load). Any levee system that is not adequately designed to withstand a wide range of hydrodynamic loads for extensive durations is susceptible to erosion-induced breaching failure.

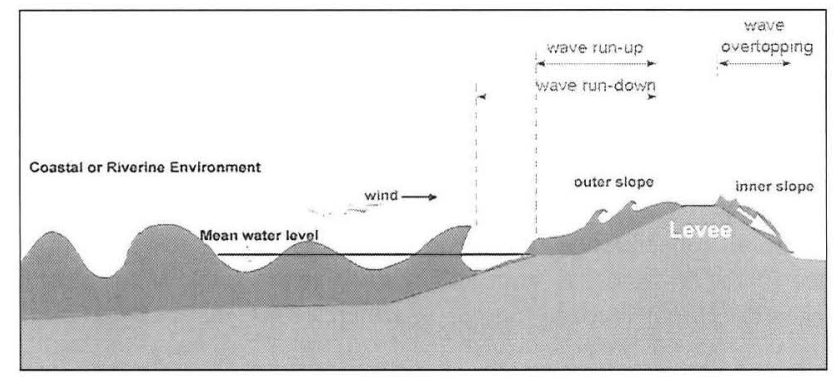

Figure 1. Diagram of potential hydrodynamic forcing on a levee structure.

Erosion effectively reduces the levee cross-sectional area (width) by physically removing soil from either side of the levee, and extensive damage negatively af- 
fects the structural integrity. Levee maintainenance provides resilience and perpetuates successful performance.

Levee maintenance costs are not normally resourced using a reliability assessment approach based on analytical models (FEMA 2008, USACE 1996). An erosion-damaged levee reach is generally repaired as a response to a storm event by using fill dirt or riprap from a stockpiled supply source. What-if scenarios of expected levee damage occurring from a storm or flood event are generally subjective, based on local experience or judgement. Figure 2 illustrates two such possible levee erosion and subsequent damage repair scenarios. If outer slope erosion initiates and progressively damages the levee, a post-storm repair effort (e.g. dump truck and bulldozer) typically mitigates the damage. In lieu of (or in addition to) outer slope damage, the inner slope may be overtopped and eroded. The inner slope or crest is then repaired in a similar fashion. If repairs and maintenance are performed in a timely manner, the levee structure will be ready for exposure to the next storm event.

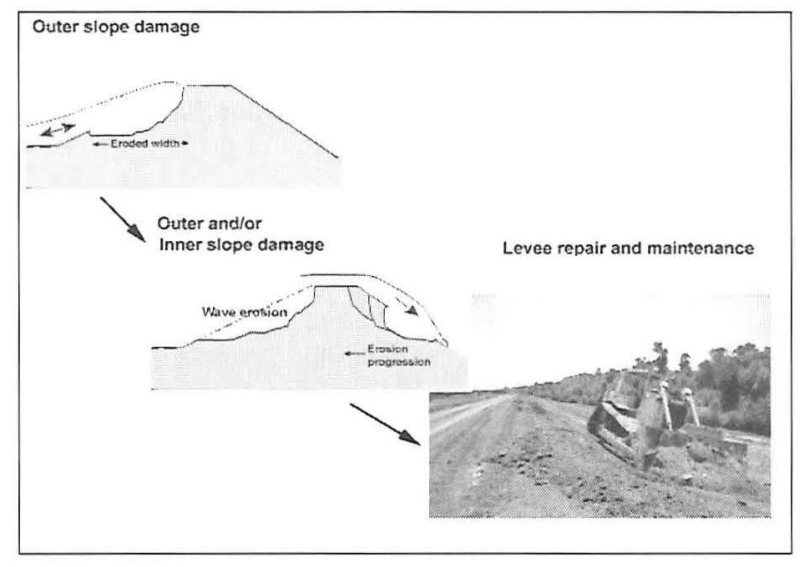

Figure 2. Eroded levee restoration and maintenance.

Utilizing a reliability assessment model to estimate the conditional probability of erosion-induced breaching (i.e. unsatisfactory performance) becomes increasingly important if the levee is protecting property or population. Figure 3 illustrates the possible eventual consequence of inadequate intervention, restoration, or long-term maintenance of the levee cross sectional width. If the levee's integrity is not maintained, any subsequent hydrodynamic loading event may cause erosion-induced breaching. 


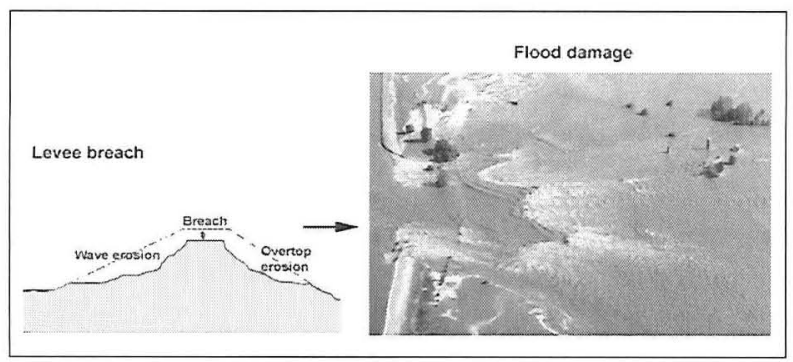

Figure 3. Illustration of a breach possibly due to inadequate levee restoration or long-term maintenance.

Figure 4 shows a framework of steps to estimate levee erodibility, forecast cross section erosion volumes, and assess risk reduction alternatives for minimizing levee life-cycle flood damages.

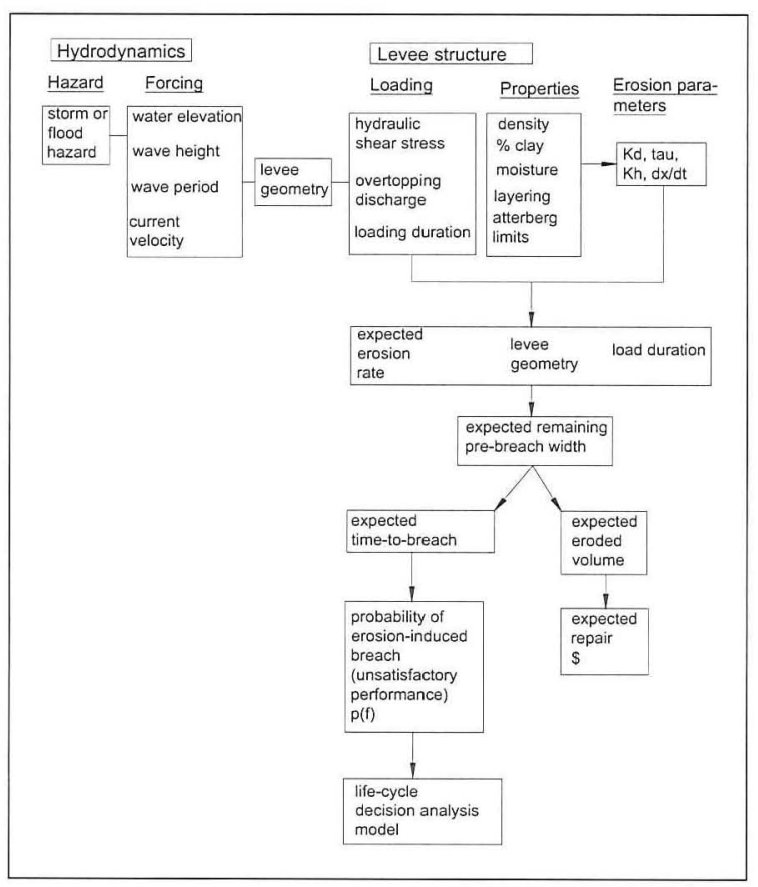

Figure 4. Levee erosion model flow chart showing a framework for addressing (a) expected erosion repair costs and/or (b) life-cycle flood risk reduction analysis. 


\section{LEVEE EROSION}

In the United States, levee erosion-induced breaching is receiving more attention as a potential failure mode (IPET 2007). Predicting levee erosion and erosioninduced breaching caused by transient hydrodynamic loads is a largely uncertain exercise and the very few models that have been developed (including the one addressed in this paper) have not been validated on existing levees. Very little experimental research has related hydrodynamic (storm surge and wave action) parameters to erosion of fine-grained (cohesive) levees (USACE 2007).

Erosion rate is a function of hydrodynamic loading and soil strength. Eroded volume is a function of erosion rate and hydrodynamic loading exposure time (duration). The longer a storm surge acts on a levee face, the greater the potential eroded volume (width, depth, and length). As the storm progresses and intensifies, loading may also develop on the levee crest and inner slope. Time-dependent hydrodynamic loading on coastal structures is a relatively recent modeling capability (Melby, 2008; Nadal and Melby, 2009; Lynett et al., 2010; Dean et al., 2010). Little is known about the mechanisms of wave-induced time-dependent erosion or modeling of breaking wave runup and overtopping on levees, and empirical erosion parameters were generally developed from steady-state loading scenarios. However, usage of the empirical parameters may arguably be appropriate for reliability modeling if parameter and model uncertainties are addressed. The methodology herein was based on such an assumption and was developed for quantifying erosion damage probabilities along selected coastal levee reaches (Lee 2010).

Erosion-induced breaching of a predominately fine-grained levee (illustrated in Figure 5) occurs when either (a) the outer slope erodes up to the levee crest (Figure 6), (b) the levee crest erodes (Figure 6), (c) the inner slope erodes backwards up to the levee crest (Figure 7), or (d) combined erosion (Figure 8). These simplified illustrations are patterned after embankment erosion observations and research conducted by Ralston (1987), Temple et. al (2005) and Hanson et. al (2005).

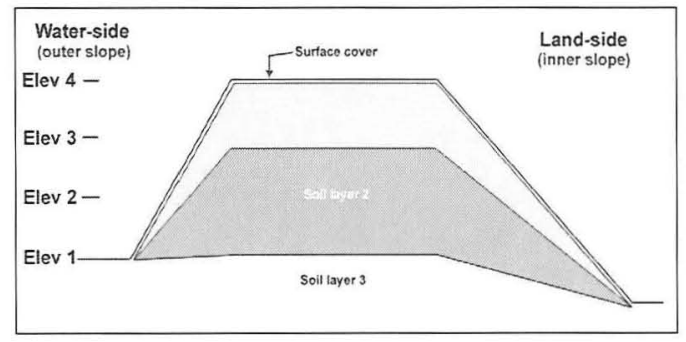

Figure 5. Cross-sectional slice through a multi-layered levee. 


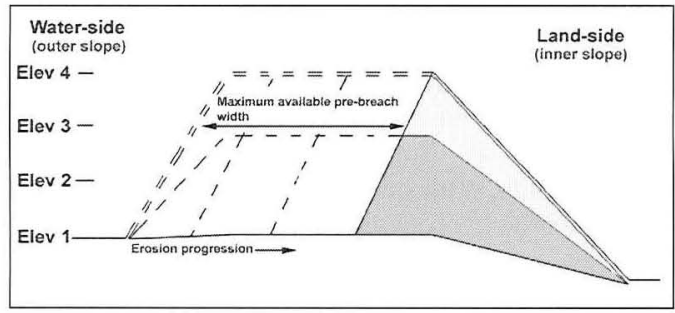

Figure 6. Conceptual outer slope erosion progression scenario

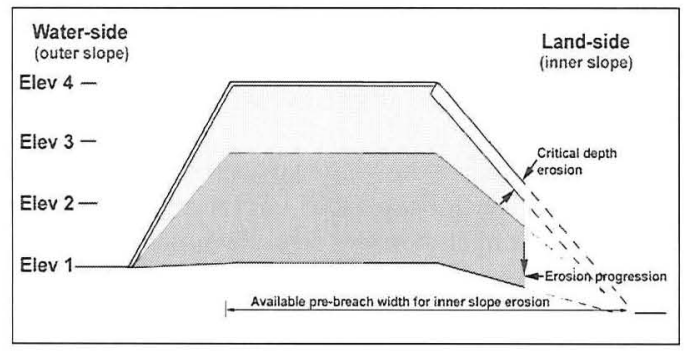

Figure 7. Conceptual inner slope erosion beginning at the levee toe

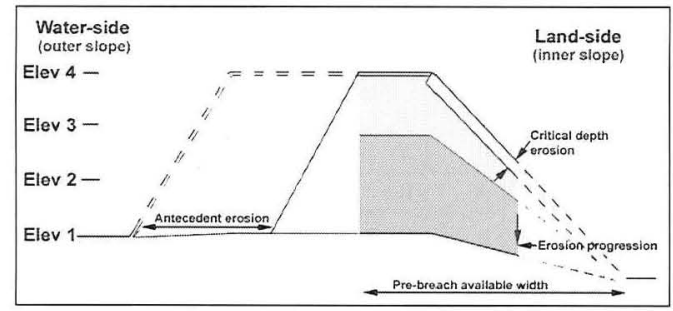

Figure 8. Conceptual combined outer slope and inner slope erosion

Modeling the levee damage from wave action and hydrodynamic loading requires estimation of the erosion rate. The estimation of the erosion rate, $\varepsilon$, is based on the textbook equation

$$
\varepsilon=\mathrm{K}_{\mathrm{d}}\left(\tau-\tau_{\mathrm{c}}\right)
$$

$\mathrm{K}_{\mathrm{d}}=$ erodibility coefficient

$\tau=$ hydrodynamic shear stress

$\tau_{\mathrm{c}}=$ limiting, or critical, soil shear strength 
The erodibility coefficient and critical shear strength values are based on empirical relationships or experimental data. Procedures for selecting these values are found in Temple et. al (2005) and Hanson et. al (2005). Guidance for estimating headcut advance and other erosion process parameters are found in NRCS (1997, 2001). Uncertainty variables are discussed in URS (2007). The hydrodynamic shear stress, overtopping flow rates, and their uncertainty variables are also needed. Nadal and Melby (2009) discuss the hydrodynamic parameters.

\section{EROSION PROBABILITY}

As diagrammed in Figure 4 above, the expected remaining levee width was calculated first. The expected remaining levee width is a function of expected hydrodynamic parameters (outer slope shear stress, inner slope overtopping flow rate, and exposure time). Estimating the expected remaining levee width is necessary for (a) estimating eroded cross-sectional area (volume) and (b) estimating the probability of unsatisfactory performance for subsequent risk assessment.

Figure $\mathbf{1 0}$ is a lookup table showing expected remaining levee widths for a selected levee cross section. The lookup table format allows modeling of cumulative storm events in addition to single storm events. Each tabulated value was developed by calculating expected erosion rate and its uncertainty for a given levee crosssection. Each input variable was assigned as a lognormal probability distribution function and each equation's expected (central tendency or mean) value was calculated using statistical software Monte Carlo simulations.

\begin{tabular}{|l|l|l|l|l|l|l|l|}
\hline $\begin{array}{l}\text { Hydraullc shear } \\
\text { stress, psf }\end{array}$ & 0.1 & 0.3 & 0.5 & 1 & 2 & 3 & 4 \\
\hline Exposure, ,hr & \multicolumn{6}{|c|}{ Expected remaining levee wldth prlor to breaching, ft } \\
\hline 0 & 8 & 8 & 8 & 8 & 8 & 8 & 8 \\
\hline 0.2 & 8 & 8 & 7.9 & 7.8 & 7.6 & 7.3 & 7 \\
\hline 0.4 & 8 & 8 & 7.9 & 7.6 & 7.1 & 6.6 & 6 \\
\hline 0.8 & 8 & 8 & 7.8 & 7.3 & 6.2 & 5.2 & 4.1 \\
\hline 1 & 8 & 8 & 7.7 & 7.1 & 5.8 & 4.5 & 3.2 \\
\hline 2 & 8 & 8 & 7.5 & 6.2 & 3.6 & 1 & 0 \\
\hline 3 & 8 & 8 & 7.2 & 5.3 & 1.4 & 0 & 0 \\
\hline
\end{tabular}

Figure 10. Example lookup table of expected remaining levee widths for a multilayered clay levee with an 8-ft crest width (Lee 2010).

\section{Probability of Unsatisfactory Performance}

Erosion parameters were calculated using the NRCS $(1997,2001)$ equations within a probabilistic framework. The expected critical times to breach were computed by dividing the tabulated remaining width values by the erosion rate expected value (mean) and standard deviation values, also generated by Monte Carlo simulations. The computed critical breach times were then formulated as limit state func- 
tions by comparing critical times to expected exposure times. Next, the conditional probability of erosion-induced breaching failure value was obtained using the textbook limit state method for calculating the reliability index (Harr 1987). The reliability index $(\beta)$ values were generated as simulation outputs. Each conditional probability value, $\mathrm{p}(\mathrm{f})$, was then computed from the standard normal distribution. The conditional probability values represented the erosion-induced breaching conditional probability for either the outer slope, crest, or inner slope, or combinations thereof. Figure $\mathbf{1 1}$ is an example conditional probability lookup table for a selected levee cross section.

\begin{tabular}{|c|c|c|c|c|c|c|c|c|c|c|c|c|c|}
\hline \multicolumn{14}{|c|}{ Probabillty of eroslon-Induced levee fallure, $p(f)$} \\
\hline \multirow{2}{*}{$\begin{array}{l}\text { Critical } \\
\text { time to } \\
\text { breach, } \\
\text { hr }\end{array}$} & \multicolumn{13}{|c|}{ Exposure time, hr } \\
\hline & 0.2 & 0.4 & 0.6 & 0.8 & 1 & 12 & 14 & 16 & 18 & 2 & 3 & 4 & 5 \\
\hline 9.2 & 0.02 & 0.02 & 0.02 & 0.03 & 0.03 & 0.03 & 0.04 & 0.04 & 0.05 & 0.05 & 0.08 & 0.12 & 0.17 \\
\hline 3.4 & 0.03 & 0.04 & 0.05 & 0.06 & 0.08 & 0.10 & 0.12 & 0.14 & 0.17 & 0.20 & 0.40 & 0.62 & 0.81 \\
\hline 0.8 & 0.07 & 0.17 & 0.33 & 0.54 & 0.72 & 0.86 & 0.94 & 0.98 & 0.99 & 1.00 & 1.00 & 1.00 & 1.00 \\
\hline
\end{tabular}

Figure 11. Conditional probability lookup table from an example levee cross section (Lee 2010).

\section{Risk Reduction Analysis}

Estimating the probability of unsatisfactory performance is needed to conduct risk reduction simulations. Projecting the hydrodynamic loads (expected values and standard deviations) on a given levee structure allows probabilistic forecasting of subsequent flood damages to property and population. Knowing the probability of failure and the failure consequences allows economic decisions to be quantified. For example, knowing that a given levee reach has a higher probability of failure may justify allocation of additional long-term maintenance resources to prevent that reach from failing due to erosion-induced breaching. Other failure modes (stability, seepage, etc.) may also be included in the risk analysis.

Figure 12 illustrates components needed to conduct long-term erosion risk reduction decision analyses. This flow chart illustrates only one potential approach to life-cycle decision analysis. The level of detail and component sophistication will de- 
pend on numerous other factors such as including additional potential failure modes (i.e. underseepage and stability), availability of hydrodynamic data, ability to quantify elevation exceedance curves, methodologies to quantify life-cycle damages (consequence analyses), and quantifying risk reduction costs, to list a few. The purpose of this illustration is to show that the pre-requisite module is a levee erosion model that quantifies the probability of unsatisfactory performance $p(f)$. The $p(f)$ calculations are based on geotechnical evaluation of the soil erodibility linked to expected hydrodynamic loading that explicitly includes uncertainty.

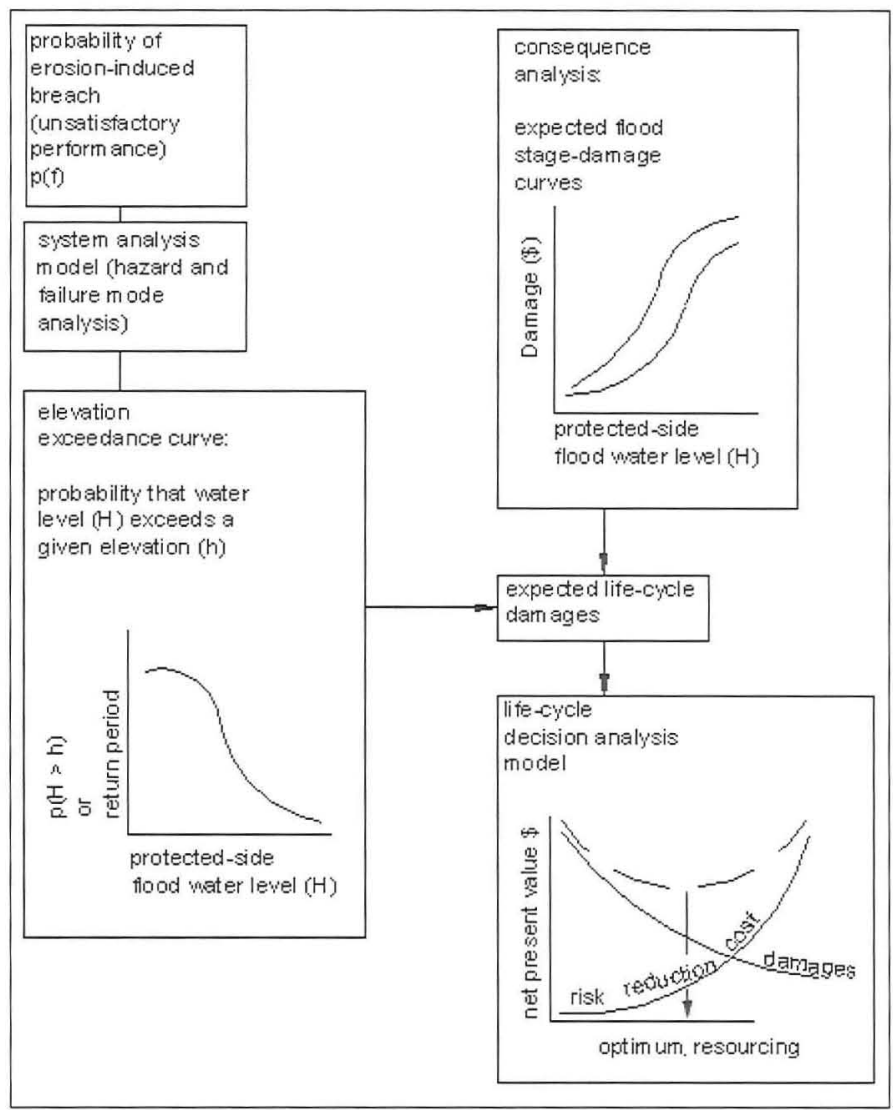

Figure 12. Flow chart illustrating necessary components for one approach to life-cycle flood risk reduction analysis utilizing a probabilistic levee erosion model. 


\section{CONCLUSION}

Development of a probabilistic erosion model enabled the expected levee erosion damage (caused by episodic or cumulative storm events) to be quantified. The ability to forecast the expected levee maintenance costs and evaluate flood risk reduction economics are logical extensions of this model. Although not addressed in detail herein, these life-cycle issues may be modeled by extending the original erosion model functions to include damage and decision analysis modules.

\section{REFERENCES}

Dean, R.G., Rosati, J.D., Walton, T.L., and Edge, B.L. (2010). "Erosional equivalences of levees: Steady and intermittent wave overtopping," Ocean Engineering 37, $104-113$.

FEMA (2008). "Guidance for coastal flood hazard analyses and mapping in sheltered waters," Technical Memorandum, Dept. of Homeland Security, February, 22 pages.

Hanson, G.J., Temple, D.M., Morris, M., Hassan, M., and Cook, K.R. (2005). "Simplified breach analysis model for homogeneous embankments: Part II, Parameter inputs and variable scale model comparisons", Proceedings of the 2005 U.S. Society on Dams Annual Meeting and Conference, Salt Lake City, UT, pp: 163 - 174.

Harr, M.E. (1987). Reliability-based design in civil engineering, Dover Publications, Mineola, NY.

Interagency Performance Evaluation Team (IPET) (2007). Performance Evaluation of the New Orleans and Southeast Louisiana Hurricane Protection System, Interim Draft Final Report of the Interagency Performance Evaluation Task Force, Volumes 1 through 9, U.S. Army Corps of Engineers, Washington, D.C. http:/ipet,wes.army.mil/

Lee, L. T. (2010). "Reliability assessment of South San Francisco Bay shoreline levees," ERDC Technical Report (in publication), U.S. Army Engineer Research and Development Center, Vicksburg, MS.

Lynett, P.J., Melby, J.A., and Kim, D. (2010). "An application of Boussinesq modeling to hurricane wave overtopping and inundation," Ocean Engineering, 37, 135 153.

Melby, J.A. (2008). "Time-dependent life-cycle analysis of coastal structures," In Press, Proc. of Coastal Structures 2007, ASCE, Reston, VA.

Nadal, N. C. and Melby, J. A. (2009). "Wave runup and overtopping analysis for South San Francisco Bay Shoreline Study," ERDC Technical Report (in publication), U.S. Army Engineer Research and Development Center, Vicksburg, MS. 
NRCS (1997). Chapter 51, Earth spillway erosion model, in USDA National Engineering Handbook, Part 628 Dams

NRCS (2001). Chapter 52, Field procedures guide for the headcut erodibility index, in USDA National Engineering Handbook, Part 628 Dams

Ralston, D.C. (1987). "Mechanics of embankment erosion during overflow," Proc., Hydraulic Engineering, 1987, ASCE, New York, 733-738.

Temple, D.M., Hanson, G.J., Neilsen, M.L., and Cook, K.R. (2005). "Simplified breach analysis model for homogeneous embankments: Part I, Background and model components", Proceedings of the 2005 U.S. Society on Dams Annual Meeting and Conference, Salt Lake City, UT, pp: 151 - 161.

URS (2007). Erosion toolbox user's manual: Levee risk assessment methodology, prepared for US Army Corps of Engineers' Nationwide Levee Risk Assessment Program, Washington, D.C.

USACE (1996). Engineering and design: Risk analysis for flood damage reduction studies," Engineer Manual 1110-2-1619, U.S. Army Corps of Engineers, Washington, D.C.

USACE (2007). "Certification of levee systems for the National Flood Insurance Program," Draft ETL 1110-2-570, U.S. Army Corps of Engineers, Washington, D.C. 